\title{
Inflammation induced by lipopolysaccharide advanced androgen receptor expression and epithelial-mesenchymal transition progress in prostatitis and prostate cancer
}

\author{
Guang-Chun Wang ${ }^{1 \#}$, Tian-Run Huang ${ }^{1,2 \#}$, Ke-Yi Wang ${ }^{1 \#}$, Zong-Lin Wu ${ }^{1}$, Jin-Bo Xie ${ }^{1}$, \\ Hou-Liang Zhang ${ }^{1}$, Lei Yin ${ }^{1}$, Wen-Long Tang ${ }^{3}$, Bo Peng ${ }^{1}$ \\ ${ }^{1}$ Department of Urology, Shanghai Tenth People's Hospital, Tongji University School of Medicine, Shanghai, China; ${ }^{2}$ Department of Urology, \\ Shanghai Traditional Chinese Medicine Hospital, Shanghai University of Traditional Chinese Medicine, Shanghai, China; ${ }^{3}$ Department of Urology, \\ People's Hospital of Lincang, Lincang, China \\ Contributions: (I) Conception and design: GC Wang, TR Huang; (II) Administrative support: WL Tang, B Peng; (III) Provision of study materials or \\ patients: ZL Wu, JB Xie, HL Zhang; (IV) Collection and assembly of data: KY Wang; (V) Data analysis and interpretation: L Yin; (VI) Manuscript \\ writing: All authors; (VII) Final approval of manuscript: All authors. \\ "These authors contributed equally to this work. \\ Correspondence to: Bo Peng. Department of Urology, Shanghai Tenth People's Hospital, Tongji University School of Medicine, Shanghai 200072, \\ China. Email: bopeng0611@126.com.
}

\begin{abstract}
Background: To explore the mechanism of prostatic inflammation on prostate cancer (PCa) by comparing the changes of prostate epithelial cells and PCa cells in an inflammatory environment.

Methods: First, immunohistochemistry (IHC) was used to compare the level of expression of TNF- $\alpha$, IL-1 $\beta$, IL-6, and TGF- $\beta$ between benign prostatic hyperplasia (BPH), prostatitis, and PCa. Then primary prostate epithelial cells were sampled from patients who were suspected of PCa and had histological prostatitis (HP) confirmed by pathological biopsy. Lipopolysaccharide (LPS) or BAY11-7082 were used to investigate the change of androgen receptor (AR) and AR-mediated transcription, epithelial-mesenchymal transition (EMT) in primary prostate epithelial cells, and lymph node carcinoma of the prostate (LNCap) cells.
\end{abstract}

Results: TNF- $\alpha$, IL- $1 \beta$, IL-6, and TGF- $\beta$ were significantly increased in HP and PCa compared with those in BPH patients. The proliferation of primary prostate epithelial cells and LNCap cells got the inflection point at LPS $10 \mu \mathrm{g} / \mathrm{mL}$. In an inflammatory environment with $10 \mu \mathrm{g} / \mathrm{mL}$ LPS, both primary prostate epithelial cell and LNCap cell viability increased, and $A R, A R$-mediated transcription, and EMT processes were significantly increased. Inhibitors of $N F-\kappa B$ with $10 \mathrm{nM}$ BAY11-7082 decreased $A R, A R$ mediated transcription, and EMT processes.

Conclusions: $N F-\kappa B$ regulates $A R$ expression and EMT in prostatitis and $\mathrm{PCa}$, and $N F-\kappa B$ inhibitors may have potential therapeutic value.

Keywords: Prostatitis; prostate cancer (PCa); lipopolysaccharide (LPS); epithelial-mesenchymal transition (EMT)

Submitted Sep 22, 2021. Accepted for publication Nov 18, 2021.

doi: $10.21037 /$ tau-21-964

View this article at: https://dx.doi.org/10.21037/tau-21-964

\section{Introduction}

Prostate cancer $(\mathrm{PCa})$ is the most frequently diagnosed cancer and the second leading cause of cancer-related death among American men (1). The occurrence and development of PCa may involve a variety of genes and signal pathways, such as androgen receptor $(A R)$ signaling (2). The average response time of castration treatment for patients with advanced PCa only lasts for 18 to 24 months, and PCa will 
eventually develop into castration-resistant prostate cancer (CRPC) (3). How to effectively prevent the occurrence of $\mathrm{PCa}$ is a challenge faced by every urologist.

Prostatitis is the most common diagnosis in men below 50 years (4). Prostatitis refers to prostate inflammation presenting with lower urinary tract symptoms and sexual dysfunction. Up to $15 \%$ of men may suffer from prostatitis (5). Studies have demonstrated that chronic prostatitis/chronic pelvic pain syndrome (CP/CPPS) involves a complex pathophysiology, including infectious, immunologic, neurologic, endocrinologic and psychologic etiologies, with frequent intersections between the different entities (6). There is substantiating evidence to support the role of cytokines in prostatitis pathogenesis $(7,8)$. Long-term inflammatory stimulation is closely related to tumorigenesis (9), with about $20 \%$ of tumors being related to inflammation (10), suggesting cytokine cascades, such as TNF- $\alpha$, IL- 6 , and TGF- $\beta$, as manifestations of the underlying paraneoplastic systemic disease (11). The incidence of PCa in prostatitis had not been widely reported. Kim $\mathrm{SH}$ reported the incidence of $\mathrm{PCa}$ in prostatitis was $1.64 \%$. Furthermore, the patients with prostatitis had a higher risk of PCa than the patients without prostatitis (12). Chronic asymptomatic prostatitis was detected in $31 \%$ patients with $\mathrm{PCa}$, and there was a positive correlation between the inflammation aggressiveness grade and urological pathology grades. The aggressiveness of intraprostatic inflammation may be an important morphological factor affecting the Gleason score (13). In prostate lesions, focal prostate inflammatory atrophy (PIA) or high-grade prostate intraepithelial neoplasia (HGPIN) is often associated with infiltrating immune cells (14), which have been discussed in connection with early cancer development (15). These results implicate that inflammatory events in PIA may potentially contribute to the development of HGPIN and PCa. However, whether there is a direct causal interaction between cytokine cascades in inflammation and epithelial cells that result in tumor initiation is still not clear.

Compared with former study (16), LNCap cells and primary prostate epithelial cells were be used in this study to investigate $\mathrm{NF}-\mathrm{\kappa B}$ regulates $\mathrm{AR}$ expression and $\mathrm{EMT}$ in prostatitis and PCa. Compared with DU145 cells and PC3 cells, LNCap cells showed more androgen-sensitive and have remarkable epithelial properties, which widely used in EMT research (17). What's more, this is the first time to apply primary prostate epithelial cells, which sampled from patients who were suspected of PCa and had histological prostatitis (HP) confirmed by pathological biopsy, in prostatitis-PCa-EMT research. In our study, BAY11-7082, an inhibitor of NF- $\mathrm{kB}$, used to suppressed LPS-mediated cells activation and abrogated the direct pro-migratory effect of LPS on cells. BAY11-7082 acts by inhibiting TNF$\alpha$-induced phosphorylation of IкB- $\alpha$, resulting in decreased $\mathrm{NF}-\mathrm{\kappa B}$ and decreases expression of adhesion molecules. BAY11-7082 completely suppresses the LPS-stimulated and IL-1-stimulated phosphorylation of the activation loop of IKK $\beta$.

In this study, we extracted prostatic epithelial cells from patients with suspected $\mathrm{PCa}$ and simple prostatitis confirmed by pathological biopsy, where lipopolysaccharide (LPS) and BAY11-7082 were used to test the change of inflammatory factor secretion, AR, AR-mediated transcription, and epithelial-mesenchymal transition (EMT) in primary prostate epithelial cells and lymph node carcinoma of the prostate (LNCap) cells. We present the following article in accordance with the MDAR reporting checklist (available at https://dx.doi.org/10.21037/tau-21-964).

\section{Methods}

\section{Clinical date}

Seventy-seven patients were enrolled through the Department of Urology, Shanghai Tenth People's Hospital, from 2019 to 2020. Of these, 53 patients received plasma kinetic transurethral resection of the prostate; 32 patients were confirmed as having simple benign prostatic hyperplasia (BPH) with postoperative pathological diagnosis, with a mean age of 67 (range, 60-76) years; and 21 patients as having BPH combined with HP, with a mean age of 64 (range, 58-81) years. The remaining 24 PCa patients were diagnosed by preoperative biopsy, underwent laparoscopic radical prostatectomy, and were confirmed as having $\mathrm{PCa}$ using postoperative pathology. The study was approved by ethics board of Shanghai Tenth People's Hospital (No. 2019K-69) and informed consent was taken from all the patients. The study was conducted in accordance with the Declaration of Helsinki (as revised in 2013).

\section{Immunobistochemistry (IHC)}

Specimens was prepared in paraffin sections, and $3 \% \mathrm{H}_{2} \mathrm{O}_{2}-$ methanol solution was added to inactivate the enzymes after antigen retrieval. After rinsing with phosphate-buffered saline (PBS) three times, $50-100 \mu \mathrm{L}$ normal goat serum was 
added and incubated for $20 \mathrm{~min}$ at room temperature, then the first antibody was removed and incubated in a wet box for 2 h. Anti-TNF- $\alpha$ (ab1793), anti-IL-1 $($ ab9722), antiIL-6 (ab245770) and anti-TGF- $\beta$ (ab31013) were obtained from Abcam company. After rinsing with PBS three times, $50 \mu \mathrm{L}$ enhancer was added and incubated for $30 \mathrm{~min}$. After rinsing with PBS three times, the second antibody was added and incubated for 30 min. Following rinsing with PBS and dyeing with diaminobenzidine (DAB), hematoxylin staining took place for $10 \mathrm{~min}$ followed by dehydration seal. Protein expression was observed under a light microscope, and three high expression areas were selected for statistical analysis.

\section{Isolation and purification of prostate epithelial cells}

Prostate tissues of HP patients were collected and washed three times with PBS solution. After that, tissues were digested on a shaker in a Defined Keratinocyte-SFM (Thermo Fisher, Waltham, MA, USA) supplemented by Collagenase IV (Abbexa, Cambridge, UK) $200 \mathrm{U} / \mathrm{mL}$ for $30 \mathrm{~min}$ at $37^{\circ} \mathrm{C}$. The suspension was filtered through mesh to separate single cells. Cell pellets were collected using centrifugation at $200 \mathrm{~g}$ for $10 \mathrm{~min}$, then the cells were resuspended and cultured in a Defined Keratinocyte-SFM (Thermo Fisher, Waltham, MA, USA) supplemented with bovine pituitary extract and $5 \mathrm{mM}$ epidermal growth factor (EGF) at $37^{\circ} \mathrm{C}$ with $5 \% \mathrm{CO}_{2}$.

LNCap cells were propagated using RPMI 1640 (Thermo Fisher, Waltham, MA, USA) supplemented with $10 \%$ fetal bovine serum (FBS), L-glutamine ( $2 \mathrm{mM})$, penicillin $(100 \mathrm{U} / \mathrm{mL})$, and streptomycin $(100 \mathrm{mg} / \mathrm{mL})$, at $37^{\circ} \mathrm{C}$ with $5 \% \mathrm{CO}_{2}$.

\section{Cell Counting Kit-8 (CCK-8) (Sigma Aldrich, St. Louis, MO, USA)}

For cell proliferation, 5000 cells $/ 100 \mu \mathrm{L}$ were seeded into 96 wells and cultured in endothelial cell growth medium-2 (EGM-2) containing LPS (L2654, Sigma Aldrich, St. Louis, MO, USA) at varying concentrations of $0,0.1,1,10$, 100 , and $500 \mu \mathrm{g} / \mathrm{mL}$ for 12,24 , and $48 \mathrm{~h}$. Before feeding LPS, the cells were subjected to serum starvation for $24 \mathrm{~h}$. Subsequently, the viability was estimated using CCK8 according to the manufacturer's instructions. Ten $\mu \mathrm{L}$ CCK- 8 were added to $100 \mu \mathrm{L}$ EGM-2 medium in each well and incubated at $37{ }^{\circ} \mathrm{C}$ with $5 \% \mathrm{CO}_{2}$ for $4 \mathrm{~h}$, and the absorbance was measured at $450 \mathrm{~nm}$. The cell inhibition rate was calculated as $=$ absorbance in each well/absorbance in blank $\times 100 \%$. Considering the proliferation of primary prostate epithelial cells and LNCap cells got the inflection point at LPS $10 \mu \mathrm{g} / \mathrm{mL}$, higher concentrations of LPS get significantly inhibit both primary prostate epithelial cells and LNCap cells viability, LPS $10 \mu \mathrm{g} / \mathrm{mL}$ was used as standard inflammation strength for prostate epithelial cells and LNCap cells.

\section{Enzyme-linked immunosorbent assay (ELISA)}

TNF- $\alpha$ (TNF- $\alpha$ ELISA Kit, BMS223HS), IL-1 $\beta$ (IL-1 $\beta$ ELISA Kit, KE00021), IL-6 (IL-6 ELISA Kit, BMS2132 ), and TGF- $\beta$ (TGF- $\beta$ ELISA Kit, KE00002) levels were determined using an ELISA assay.

\section{Immunofluorescence staining}

Purified corpus cavernosal endothelial cells were cultured on coverslips placed in Millicell (PEZGS0816, Millipore, Burlington, MA, USA). Upon reaching 80-90\% confluency, the cells were fixed with $4 \%$ paraformaldehyde for $30 \mathrm{~min}$, permeated with Triton X-100 (Dow Chemical Company, Midland, MI, USA) for $20 \mathrm{~min}$ and blocked with $5 \%$ bovine serum albumin (BSA) for $1 \mathrm{~h}$. The cells were incubated with primary antibodies overnight at $4{ }^{\circ} \mathrm{C}$, followed by fluorescein-labeled secondary antibody for $2 \mathrm{~h}$ at room temperature. Subsequently, the nucleus was stained with 4,6-diamidino-2-phenylindole and observed under a confocal-microscope.

\section{Quantitative polymerase chain reaction (qPCR)}

Total RNA of tissue samples was extracted using TRIzol (Life Technologies, Carlsbad, CA, USA), and then the concentration and quality were measured. Messenger RNA (mRNA) was synthesized into circular DNA (cDNA). The reaction mixture consisted of $10 \mu \mathrm{L}$ of $2 \mathrm{X}$ Real-time PCR Master Mix (Thermo Fisher, Waltham, MA, USA) with $2 \mu \mathrm{L}$ primer, and $7 \mu \mathrm{L}$ diethyl pyrocarbonate (DEPC) water, and followed with predenaturation at $95{ }^{\circ} \mathrm{C}$ for $5 \mathrm{~min}, 40$ cycles of denaturation at $95{ }^{\circ} \mathrm{C}$ for $15 \mathrm{~s}$, annealing at $60{ }^{\circ} \mathrm{C}$ for $20 \mathrm{~s}$, and extension at $72{ }^{\circ} \mathrm{C}$ for $40 \mathrm{~s}$. Primer sequences of $A R, N K X 3.1$, and $P S A$ showed in Table 1.

\section{Western blot (WB)}

Cells were rinsed with PBS, dissociated with $250 \mathrm{~mL}$ ice- 
Table 1 Primer sequences of AR, NKX3.1, and PSA

\begin{tabular}{lll}
\hline Primer name & Forward primer & Reverse primer \\
\hline AR & CCAGGGACCATGTTTTGCC & CGAAGACGACAAGATGGACAA \\
NKX3.1 & CCCACACTCAGGTGATCGAG & GAGCTGCTTTCGCTTAGTCTT \\
PSA & TGCCGCACTCAGTGTTGTTAG & GCAATTCCCGCACAAGATTCT \\
GAPDH & TGTTGCCATCAATGACCCCTT & CTCCACGACGTACTCAGCG \\
\hline
\end{tabular}

GAPDH was used as an internal control. AR, androgen receptor; PSA, prostate-specific antigen; GAPDH, glyceraldehyde-3-phosphate dehydrogenase.

cold modified radioimmunoprecipitation assay (RIPA) buffer containing both protease and phosphatase inhibitors, and then collected in Eppendorf tubes (Hamburg, Germany). The lysates were sonicated for $20 \mathrm{~s}$ ( $25 \%$ power, 0.5 cycles), centrifuged $\left(12,000 \mathrm{~g}, 4^{\circ} \mathrm{C}\right)$ for $30 \mathrm{~min}$, the clear supernatants were transferred into new tubes, and the protein concentration was determined.

WBs were performed under standard conditions. An equivalent of $40 \mathrm{mg}$ protein lysate was separated on a 10 $12 \%$ polyacrylamide gel electrophoresis (SDS-PAGE) gel and then transferred to a polyvinylidene fluoride (PVDF) membrane. Then, the PVDF membrane was blocked with $5 \%$ milk at room temperature for $2 \mathrm{~h}$ and incubated with primary antibody overnight. Anti-eNOS (ab76198) was obtained from Abcam (Cambridge, UK), anti-AR (sc-7305) was obtained from Santa Cruz Biotechnology (Dallas, TX, USW), and phospho-Akt (4060) and Akt antibody (9272) were obtained from Cell Signaling Technology (Danvers, MA, USA). After washing four times in tris-buffered saline with $0.1 \%$ Tween 20 (TBST, Merck Schuchardt, Hohenbrunn, Germany) for $15 \mathrm{~min}$, the membrane was incubated for $2 \mathrm{~h}$ in the dark with horseradish peroxidase (HRP)-conjugated rabbit or mouse antibody (34160 \& 31430, Thermo Fisher, Waltham, MA, USA). The protein bands were detected with the enhanced chemiluminescence (ECL) system (Beyotime Institute of Biotechnology, Nantong, China), followed by autoradiography and quantified by densitometry. Glyceraldehyde-3-phosphate dehydrogenase (GAPDH) (sc-32233) was the internal reference.

\section{Statistical analysis}

The Student's $t$-test was used for two-group comparisons. One-way analysis of variance (ANOVA) followed by Bonferroni's test was used for multiple comparisons.

\section{Results}

Expression of TNF- $\alpha, I L-1 \beta, I L-6$, and TGF- $\beta$ in prostate tissues

Figure $1 A$ shows prostate tissues of $\mathrm{BPH}$ as a normal control compared with HP and PCa. The IHC results (Figure $1 B$ ) showed that TNF- $\alpha$, IL- $1 \beta$, IL- 6 , and TGF- $\beta$ expression levels in HP and $\mathrm{PCa}$ were significantly increased compared with $\mathrm{BPH}$ patients $(\mathrm{P}<0.05)$. Compared with $\mathrm{PCa}$ patients, the expression of TNF- $\alpha$ and TGF- $\beta$ in HP patients was significantly higher $(\mathrm{P}<0.05)$, but the expression levels of IL-1 $\beta$ and IL-6 were not significantly different $(\mathrm{P}>0.05)$. Collectively, IHC results showed that the inflammatory environment, as a disordered inflammatory mediator, played an important role in prostate tumorigenesis.

\section{Identification of prostate epithelial cells}

As shown in Figure 2, pan-cytokeratin staining (Figure 2A) is employed to identify prostate epithelial cells. Nuclear is significant (Figure 2B), cell outline is clear, and pancytokeratin expression is positive. Cell purity is over $90 \%$ based on counts (Figure 2C).

LPS treated promoted or inhibited prostate cells' growth and upregulated cytokines.

LPS was used to feed primary prostate epithelial cells and LNCap cells to facilitate a time-dependent and controlled inflammatory microenvironment in cell culture with varying concentrations from 1 to $1,000 \mu \mathrm{g} / \mathrm{mL}$. We found that both the primary prostate epithelial and LNCap cell viability rose at low LPS concentrations ( 0 to $10 \mu \mathrm{g} / \mathrm{mL}$ ) and then fell at high LPS concentrations (Figure 3A). After 12, 24, and $48 \mathrm{~h}$, the cell supernatant was collected and filtered, and then cytokine levels were measured using ELISA assay (Figure 3B). Cytokines (TNF- $\alpha$, IL-1 $\beta$, IL-6, and TGF- $\beta$ ) were significantly higher, and thus demonstrated that LPS 
A

HP

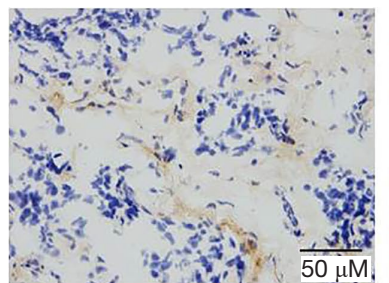

$\mathrm{PCa}$
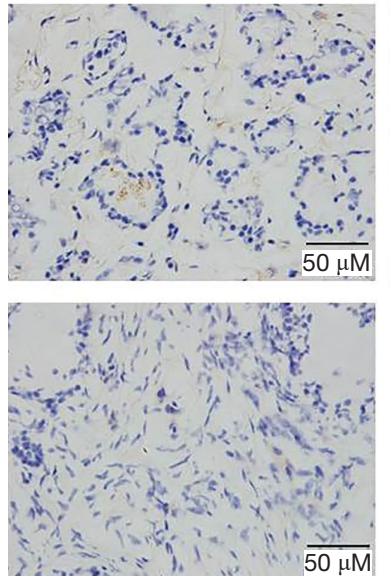

B
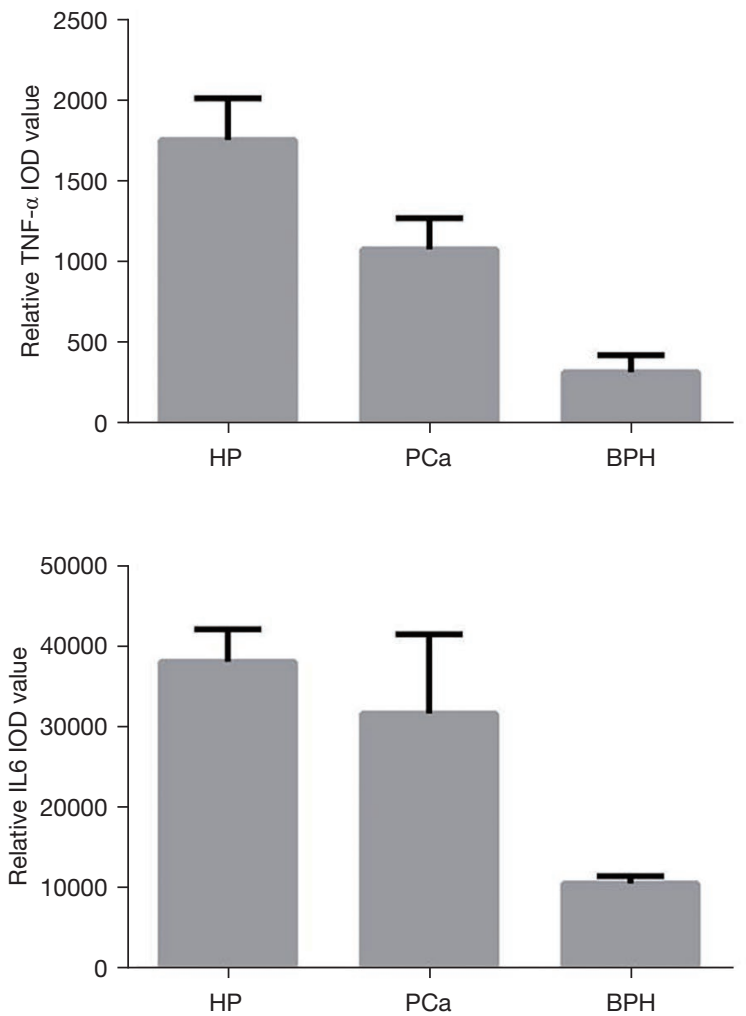

IL6
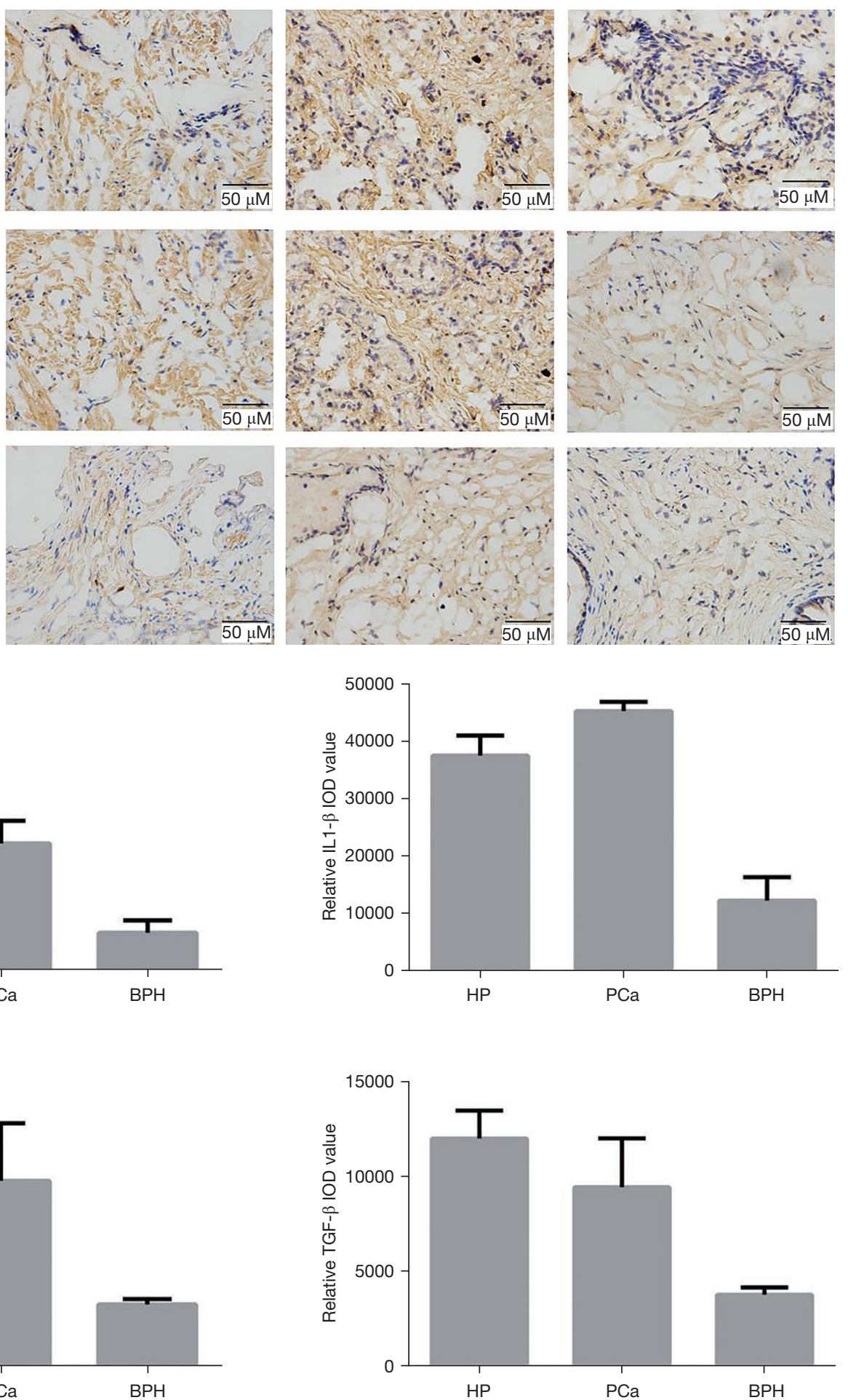

Figure 1 IHC results (A) compared the expression level of TNF- $\alpha$, IL-1 $\beta$, IL-6, and TGF- $\beta$ in HP, PCa, and BPH tissues ( $\times 200$ ). (B) IOD analysis of TNF- $\alpha$, IL-1 $\beta$, IL- 6 , and TGF- $\beta$ protein levels in HP, PCa, and BPH tissues. IHC, immunohistochemical; HP, histological prostatitis; $\mathrm{PCa}$, prostate cancer; $\mathrm{BPH}$, benign prostatic hyperplasia; IOD, integrated optical density. 

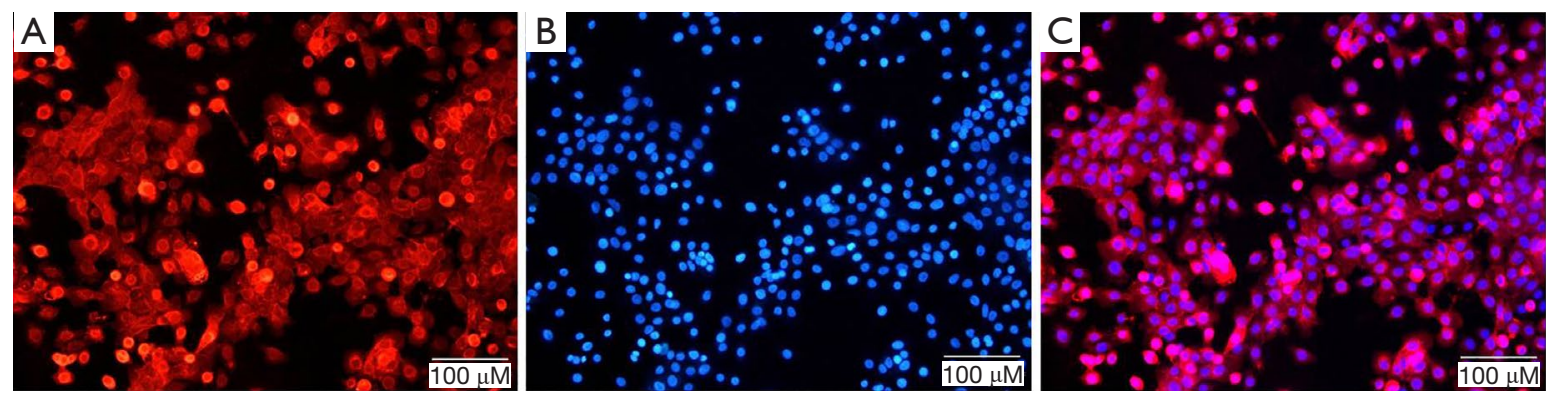

Figure 2 Identification of prostate epithelial cells. Immunofluorescence staining showed most cells expressed pan-cytokeratin (A), the cell nucleus was blue (B), and pan-cytokeratin expression was mainly expressed in the cytoplasm which was in line with the localization of cytoskeletal proteins $(\mathrm{C})$.

stimulation is effective $(\mathrm{P}<0.05)$ (see Figure 3).

LPS $10 \mu \mathrm{g} / \mathrm{mL}$ was used as standard inflammation strength for prostate epithelial cells and LNCap cells.

\section{Cell growth and secretory cytokines were suppressed by anti-inflammation BAY11-7082}

As shown in Figure 4, BAY11-7082 $10 \mathrm{nM}$ was used to feed primary prostate epithelial cells (Figure $4 A$ ) and LNCap cells (Figure $4 B$ ) as anti-inflammatory treatment. After $48 \mathrm{~h}$, both in primary prostate epithelial cells and LNCap cells, cell growth, which is mediated by LPS, was blocked and cytokines (TNF- $\alpha$, IL-1 $\beta$, IL-6, and TGF- $\beta$ ) were significantly lower $(\mathrm{P}<0.05)$ after treatment with BAY117082, showing BAY11-7082 $10 \mathrm{nM}$ for $48 \mathrm{~h}$ aggressively suppressed the inflammatory process both in primary prostate epithelial cells and LNCap cells.

\section{$W B$ results}

P65 protein expression was significantly increased $(\mathrm{P}<0.05)$ in primary prostate epithelial cells (Figure $5 A$ ) and LNCap cells (Figure $5 B$ ), showing the activation of the $N F$ $\kappa B$ signaling pathway. BAY11-7082 $10 \mathrm{nM}$ significantly inhibited p65 protein expression $(\mathrm{P}<0.05)$. Similarly, EMT markers and $\beta$-catenin were significantly decreased $(\mathrm{P}<0.05)$, while $\mathrm{N}$-cadherin was significantly increased $(\mathrm{P}<0.05)$ after treatment with LPS, and trends were reversed by blocking the $N F-\kappa B$ signaling pathway. $A R$ and MMP-9 were significantly increased in LPS and reversed after feeding with BAY11-7082 and showed time dependence $(\mathrm{P}<0.05)$.

\section{qPCR results}

The mRNA level of $A R$ was significantly increased, and prostate-specific antigen (PSA) was upregulated by 48 $\mathrm{h}$ of LPS exposure as assessed by real-time polymerase chain reaction (RT-PCR), while NKX3.1 was significantly decreased $(\mathrm{P}<0.05)$. These trends were reversed by BAY11-7082 $(\mathrm{P}<0.05)$. Primary prostate epithelial cells (Figure 6A) and LNCap cells (Figure 6B) showed the same trend $(\mathrm{P}<0.05)$ (Figure 6).

\section{Results of fluorescent staining}

Fluorescent staining of E-cadherin in primary prostate epithelial cells (Figure $7 A$ ) and vimentin in primary prostate epithelial cells (Figure 7B), E-cadherin in LNCap cells (Figure 7C), and vimentin in LNCap cells (Figure 7D) after exposure to $10 \mu \mathrm{g} / \mathrm{mL}$ LPS or $10 \mathrm{nM}$ BAY11-7082 for 12, 24 and 48 h. As shown in Figure 7, both in primary prostate epithelial cells and LNCap cells, E-cadherin (red) clearly showed lower brightness and vimentin (red) clearly showed a stronger inflammatory environment induced by LPS, and the difference increased with time. After treatment with $10 \mathrm{nM}$ BAY11-7082 as an anti-inflammatory agent, E-cadherin was clearly higher, and vimentin was clearly lower.

\section{Discussion}

Epidemiological studies show that chronic inflammation is closely related to the occurrence and development 

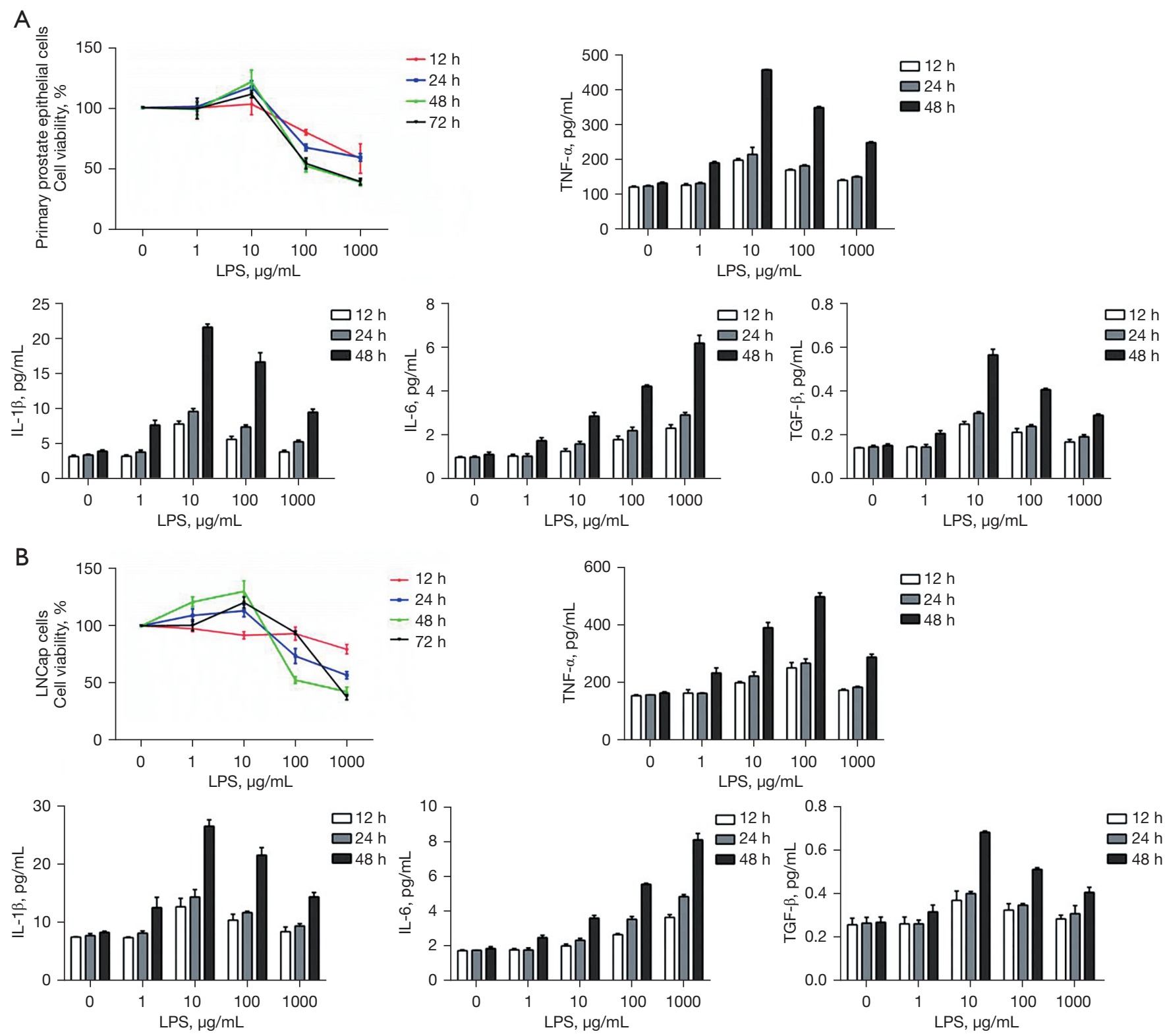

Figure 3 The increasing doses of LPS influenced proliferation (A) and cytokine levels (B) of primary prostate epithelial cells and LNCap cells. LPS, lipopolysaccharide; LNCap, lymph node carcinoma of the prostate.

of prostatic cancer (18). CP is a common finding in radical prostatectomy specimens, where peripheral zone inflammation has been reported in $95 \%$ cases, and whereby the peripheral zone is the preferred location of PCa (19). In a 5 -year follow-up study, a new cancer incidence of $20 \%$ was reported in patients with chronic inflammation (20). By contrast, a new cancer incidence of only $2 \%$ was reported in patients with adenocarcinoma initially showing no inflammation (20). After adjustment for age, family history, and other potential confounders, regular use of nonsteroidal anti-inflammatory drugs (NSAIDs) reduced PCa risks $(21,22)$.

In this study, we used Collagenase IV (Abbexa, Cambridge, UK) to isolate prostate epithelial cells, which is the most commonly agent used for tissue dissociation $(23,24)$. Also, pan-cytokeratin staining showed that the cell purity is high and suitable for research. LNCap cells were also tested. LPSs were used to stimulate cells. LPS, 

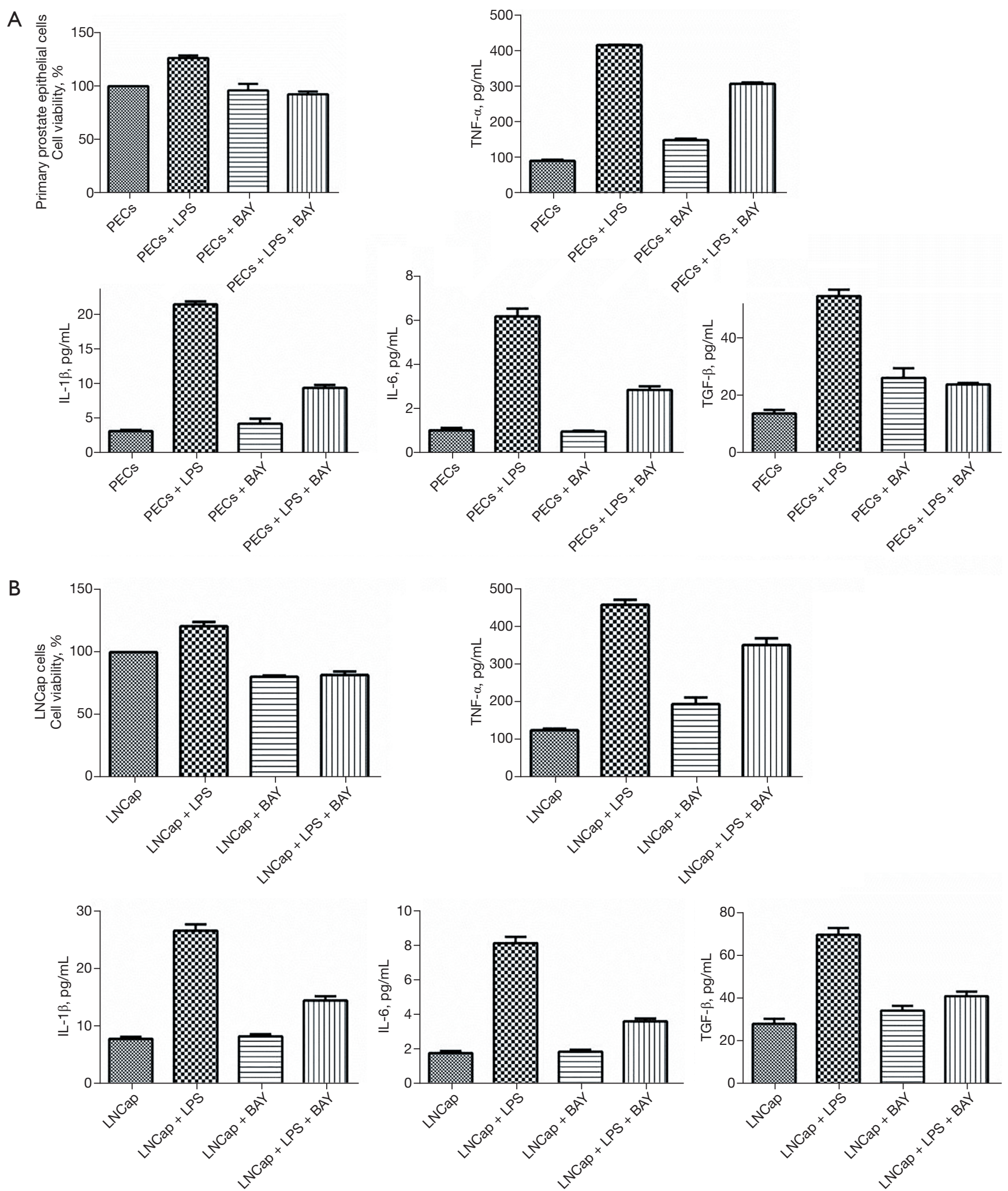

Figure 4 After 48 h, both in primary prostate epithelial cells (A) and LNCap cells (B), cell growth, which is mediated by LPS was blocked and cytokines (TNF- $\alpha$, IL-1 $\beta$, IL-6, and TGF- $\beta$ ) were significantly lower after treatment with BAY11-7082. LNCap, lymph node carcinoma of the prostate; LPS, lipopolysaccharide. 
A

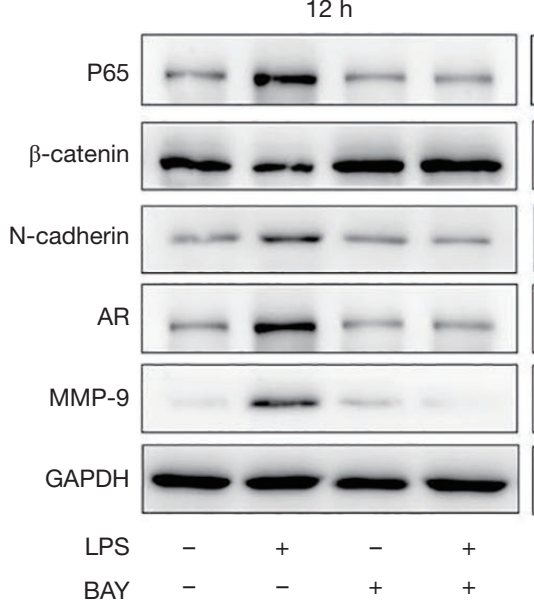

B
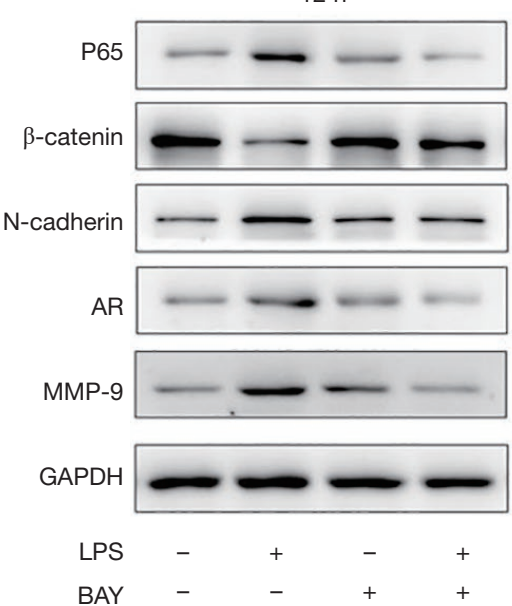

$24 \mathrm{~h}$

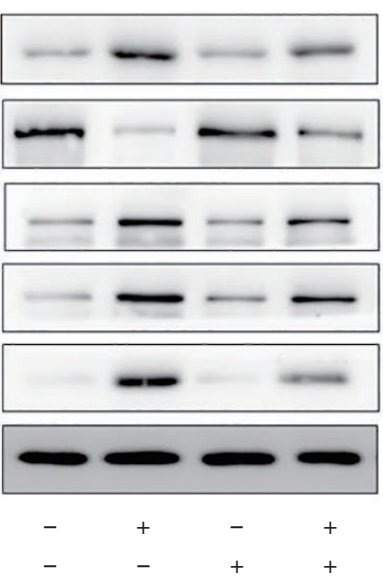

$24 \mathrm{~h}$
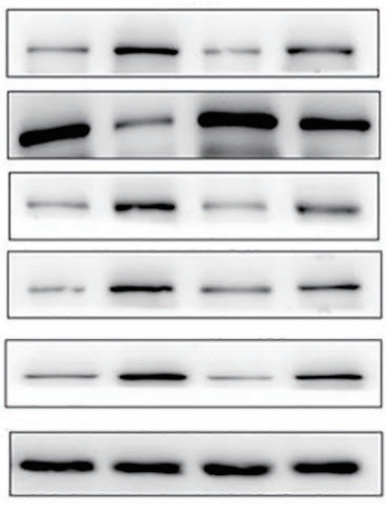

$48 \mathrm{~h}$

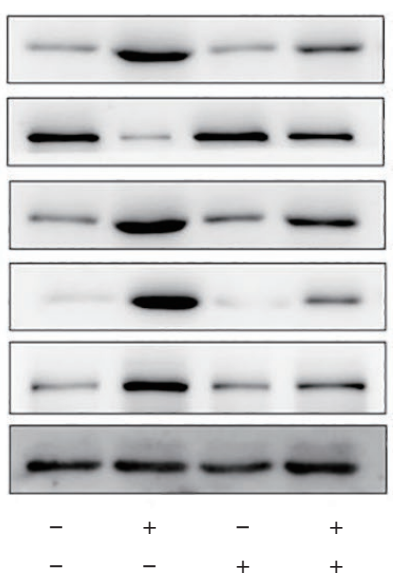

$48 \mathrm{~h}$

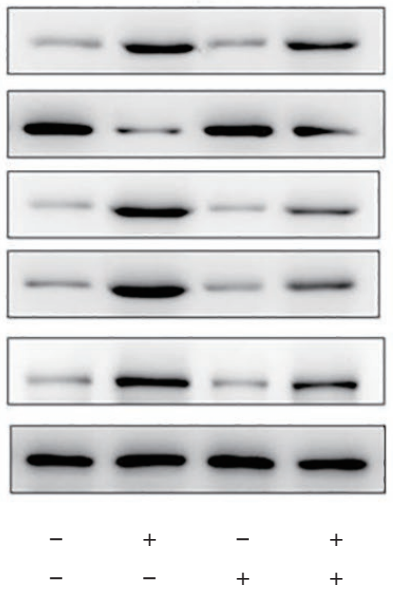

Figure $5 \mathrm{WB}$ assesses the protein level of $\beta$-catenin, N-cadherin, p65, AR, Capase-3, and MMP-9 in primary prostate epithelial cells (A) and LNCap cells (B). LPS activated the NF- $\mathrm{B}$ signaling pathway (p65) and promoted the EMT process, increased AR and MMP-9 in both primary prostate epithelial cells and LNCap cells, and trends were reversed by blocking the NF- $\kappa$ B signaling pathway with BAY117082. WB, western blot; AR, androgen receptor; LNCap, lymph node carcinoma of the prostate; LPS, lipopolysaccharide; EMT, epithelialmesenchymal transition; GAPDH, glyceraldehyde-3-phosphate dehydrogenase.

characteristic components of the cell wall of gram-negative bacteria, and lipid A can stimulate cells of the innate immune system using the toll-like receptor 4 (TLR4) (25), which recognizes common pathogen-associated molecular patterns. Also, LPS has been used to induce inflammation in vitro $(26,27)$ and has also been employed to establish a rat prostatitis model (28). In this study, we also used BAY117082, which is an inhibitor of the NF- $\mathrm{KB}$ signaling pathway, to suppress the inflammatory process. BAY11-7082 can prevent cytokine-induced IкB- $\alpha$ phosphorylation and has been widely used to reduce inflammation in a rat injury model (29).
$\mathrm{NF}-\kappa \mathrm{B}$ has initially been identified as an enhancerbinding protein for the immunoglobulin light chain in $\mathrm{B}$ lymphocytes. p65, the major activation subunit of NF$\kappa \mathrm{B}$, is an important downstream substrate of mitogenactivated protein kinase, phosphatidylinositol 3-kinase, Akt, and protein kinase C (30). Many studies have assessed the relationship of $N F-\kappa B$ expression with clinical features of human PCa. Nuclear levels of $N F-\kappa B / p 65$ correlate with $N F-\kappa B$-dependent BclII, cyclin D1, MMP-9, and $V E G F$ expression (31). Compared with benign prostatic epithelium, $N F-\kappa B / p 65$ is overexpressed in prostatic intraepithelial neoplasia and cancer (32). In addition, 

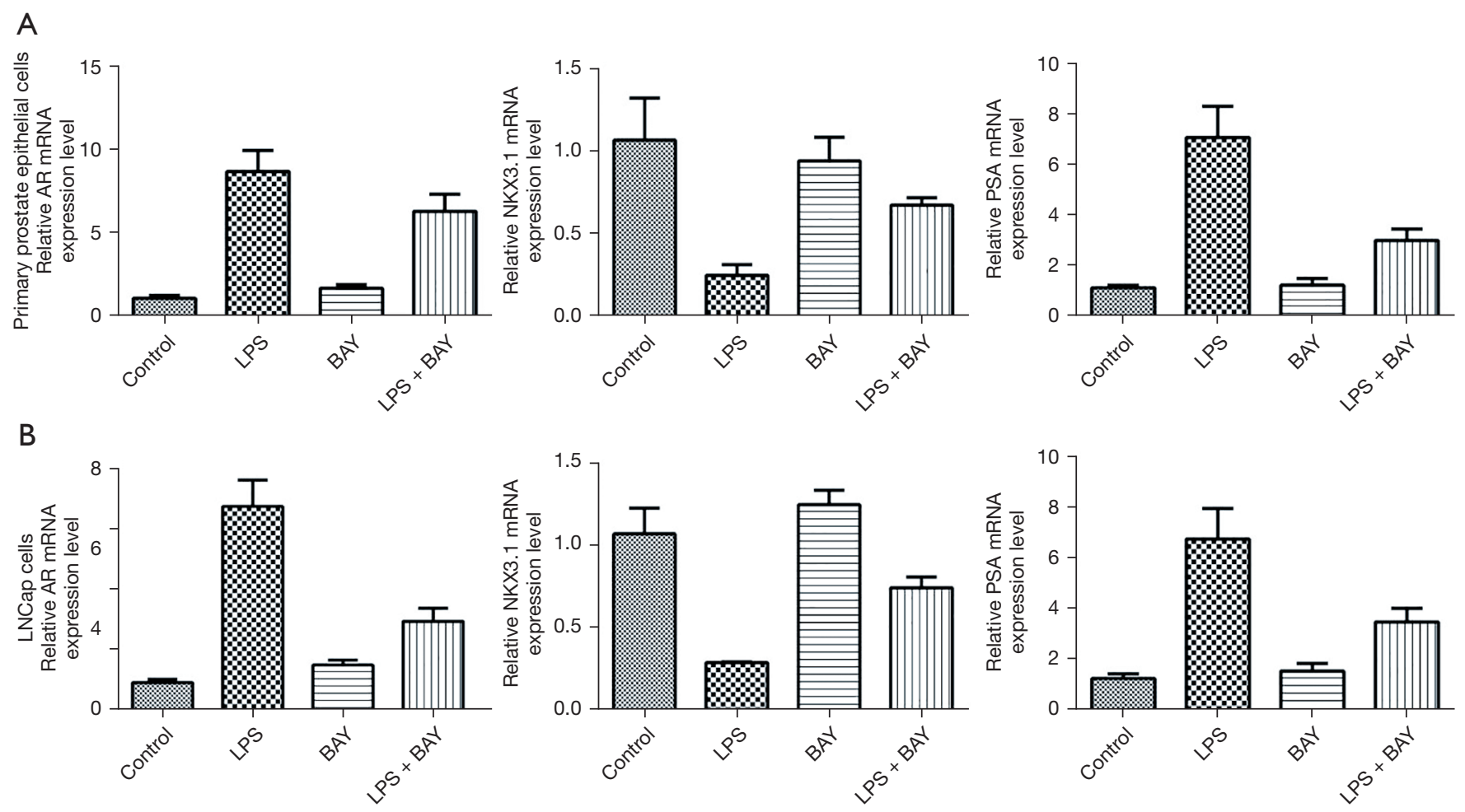

Figure 6 Both in primary prostate epithelial cells (A) and LNCap cells (B), the mRNA level of AR and PSA was significantly increased, while NKX3.1 was significantly decreased. Also, these trends were reversed by BAY11-7082. LNCap, lymph node carcinoma of the prostate; mRNA, messenger RNA; AR, androgen receptor; PSA, prostate-specific antigen; LPS, lipopolysaccharide.

$N F-\kappa B / p 65$ expression is a predictive factor of biochemical recurrence (33) and outcome (34) in patients with positive surgical margins. Jaganathan et al. (35) also demonstrated that the activation of $N F-\kappa B$ promoted the deacetylation of MYST1 and linked the transcription functions of $A R$ to escalate the resistance to therapeutic regimens and promote the aggressive growth of tumors.

The expression of $N F-\kappa B$ and the secretion of inflammatory cytokines have been shown to contribute to the production of reactive oxygen species (ROS). While certain $N F-\kappa B$-regulated genes play major roles in regulating the amount of ROS in cells and result in cell death, ROS modulates the $N F-\kappa B$ response and then activates NF- $\kappa B$ mediated transcription, and additional ROS production is reduced to promote cell survival (36). Many inflammatory cytokines may mediate the interplay of prostatic inflammation and carcinogenesis. A number of recent studies (37-39) have correlated the potential interaction of single nucleotide polymorphisms between TNF- $\alpha$, IL$1 \beta$, and TGF- $\beta$ in conferring an increased risk of PCa.
IL-6 is a cytokine involved in the etiology of PCa (40). It takes part in many innate and adaptive inflammatory processes, such as B cell activation and the acute-phase inflammatory response. Prostate cells produce IL-6 and IL6-R to promote the activation of $A R$ and are correlated with measures of PCa morbidity (18). The activation of IL-6, STAT3, and $N F-\kappa B$ maintains the epigenetic transformation of cancer cells (41).

We also reported that $N F-\kappa B$ signaling promotes EMT. EMT plays important roles in the invasion and metastasis during carcinogenesis, whereby epithelial cell-cell adhesion is decreased while the migration and invasion capacity is increased (42). The main features of EMT are transcriptional silencing of E-cadherin and upregulated mesenchymal markers such as vimentin and $\mathrm{N}$-cadherin, which is the process of cadherin switching. EMT is now recognized as an important mechanism of tumor progression and metastatic dissemination and can be induced by many stimulating factors, such as growth factors, cytokines, and hypoxia. TGF- $\beta$ is one of the most 

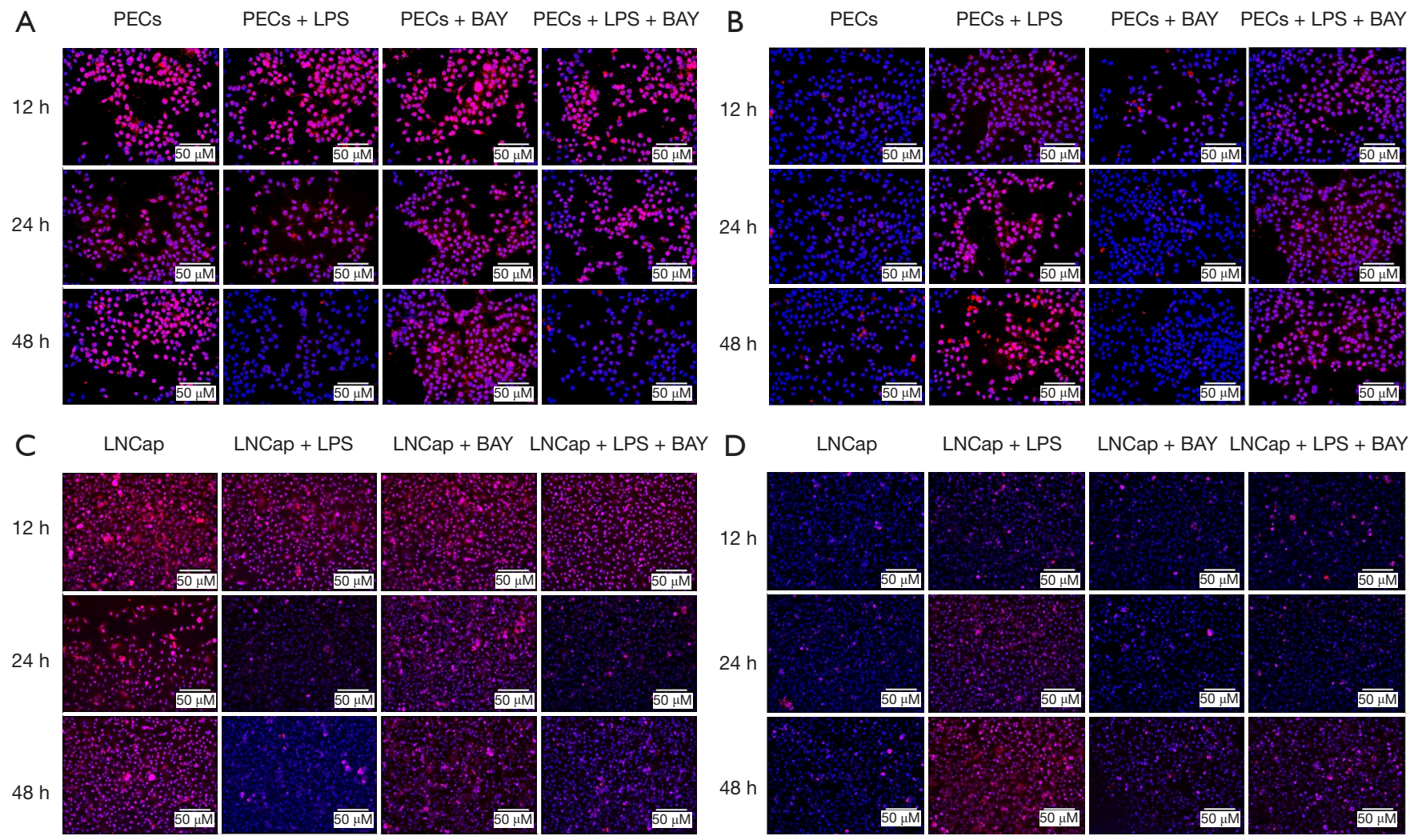

Figure 7 Fluorescent staining of E-cadherin in primary prostate epithelial cells (A) and vimentin in primary prostate epithelial cells (B), E-cadherin in LNCap cells (C), and vimentin in LNCap cells (D) after exposure to $10 \mu \mathrm{g} / \mathrm{mL}$ LPS or $10 \mathrm{nM}$ BAY11-7082 for 12, 24 and 48 h. LNCap, lymph node carcinoma of the prostate; LPS, lipopolysaccharide; PECs, prostate epithelial cells.

prominent extracellular inducers (43). Higher TGF- $\beta 1$ expression was observed in tumors with higher Gleason scores (44). Although it has been demonstrated that TGF- $\beta$ can inhibit the proliferation of tumor cells, TGF- $\beta$ can increase stronger local tumor invasiveness by inducing EMT in advanced cancers (45).

\section{Conclusions}

$N F-\kappa B$ can regulate $A R$ expression and EMT in prostatitis and $\mathrm{PCa}$, and $N F-\kappa B$ inhibitors may have a potential therapeutic value.

\section{Acknowledgments}

Funding: This study was supported by the project grant from the Shanghai Science and Technology Commission (No. 19140905402) and the Shanghai Tenth People's Hospital (No. 04.03.20125).

\section{Footnote}

Reporting Checklist: The authors have completed the MDAR reporting checklist. Available at https://dx.doi. org/10.21037/tau-21-964

Data Sharing Statement: Available at https://dx.doi. org/10.21037/tau-21-964

Conflicts of Interest: All authors have completed the ICMJE uniform disclosure form (available at https://dx.doi. org/10.21037/tau-21-964). All authors report that this study was supported by a project grant from Shanghai Science and Technology Commission (No. 19140905402) and a project grant from Shanghai Tenth People's Hospital (No. 04.03.20125). The authors have no other conflicts of interest to declare.

Ethical Statement: The authors are accountable for all 
aspects of the work in ensuring that questions related to the accuracy or integrity of any part of the work are appropriately investigated and resolved. The study was approved by ethics board of Shanghai Tenth People's Hospital (No. 2019-K-69) and informed consent was taken from all the patients. The study was conducted in accordance with the Declaration of Helsinki (as revised in 2013).

Open Access Statement: This is an Open Access article distributed in accordance with the Creative Commons Attribution-NonCommercial-NoDerivs 4.0 International License (CC BY-NC-ND 4.0), which permits the noncommercial replication and distribution of the article with the strict proviso that no changes or edits are made and the original work is properly cited (including links to both the formal publication through the relevant DOI and the license). See: https://creativecommons.org/licenses/by-nc-nd/4.0/.

\section{References}

1. Jemal A, Bray F, Center MM, et al. Global cancer statistics. CA Cancer J Clin 2011;61:69-90.

2. Shen MM, Abate-Shen C. Molecular genetics of prostate cancer: new prospects for old challenges. Genes Dev 2010;24:1967-2000.

3. Lin CY, Chuu CP. New classification may assist the development of targeted therapies for treatment-refractory castration-resistant prostate cancer. Transl Androl Urol 2020;9:837-9.

4. Potts J, Payne RE. Prostatitis: Infection, neuromuscular disorder, or pain syndrome? Proper patient classification is key. Cleve Clin J Med 2007;74 Suppl 3:S63-71.

5. Schaeffer AJ, Datta NS, Fowler JE Jr, et al. Overview summary statement. Diagnosis and management of chronic prostatitis/chronic pelvic pain syndrome (CP/ CPPS). Urology 2002;60:1-4.

6. Pena VN, Engel N, Gabrielson AT, et al. Diagnostic and Management Strategies for Patients with Chronic Prostatitis and Chronic Pelvic Pain Syndrome. Drugs Aging 2021;38:845-86.

7. Zhang H, Li F, Li WW, et al. The inflammasome as a target for pain therapy. Br J Anaesth 2016;117:693-707.

8. Jang TL, Schaeffer AJ. The role of cytokines in prostatitis. World J Urol 2003;21:95-9.

9. Shalapour S, Karin M. Immunity, inflammation, and cancer: an eternal fight between good and evil. J Clin Invest 2015;125:3347-55.
10. Coussens LM, Werb Z. Inflammation and cancer. Nature 2002;420:860-7.

11. Li H, Wang Y, Zhang $M$, et al. The high expression of TNF- $\alpha$ and NF- $\mathrm{KB}$ in tumor mi-croenvironment predicts good prognosis of patients with BCLC-0-B hepatocellular car-cinoma. Transl Cancer Res 2019;8:532-41.

12. Kim SH, Kwon WA, Joung JY. Impact of Benign Prostatic Hyperplasia and/or Prostatitis on the Risk of Prostate Cancer in Korean Patients. World J Mens Health 2021;39:358-65.

13. Aglamis E, Ceylan C, Akin MM. Is there a correlation between the aggressiveness of chronic asymptomatic prostatitis National Institutes of Health category IV and the Gleason score in patients with prostate cancer? Can Urol Assoc J 2020;14:E568-73.

14. Perletti G, Montanari E, Vral A, et al. Inflammation, prostatitis, proliferative inflammatory atrophy: 'Fertile ground' for prostate cancer development? Mol Med Rep 2010;3:3-12.

15. Puhr M, De Marzo A, Isaacs W, et al. Inflammation, Microbiota, and Prostate Cancer. Eur Urol Focus 2016;2:374-82.

16. Jain S, Dash P, Minz AP, et al. Lipopolysaccharide (LPS) enhances prostate cancer metastasis potentially through NF- $\mathrm{\kappa B}$ activation and recurrent dexamethasone administration fails to suppress it in vivo. Prostate 2019;79:168-82.

17. Singh KB, Hahm ER, Singh SV. Leelamine suppresses $\mathrm{cMyc}$ expression in prostate cancer cells in vitro and inhibits prostate carcinogenesis in vivo. J Cancer Metastasis Treat 2021;7:16.

18. Sfanos KS, De Marzo AM. Prostate cancer and inflammation: the evidence. Histopathology 2012;60:199-215.

19. Gerstenbluth RE, Seftel AD, MacLennan GT, et al. Distribution of chronic prostatitis in radical prostatectomy specimens with up-regulation of bcl-2 in areas of inflammation. J Urol 2002;167:2267-70.

20. MacLennan GT, Eisenberg R, Fleshman RL, et al. The influence of chronic inflammation in prostatic carcinogenesis: a 5-year followup study. J Urol 2006;176:1012-6.

21. Jafari S, Etminan M, Afshar K. Nonsteroidal antiinflammatory drugs and prostate cancer: a systematic review of the literature and meta-analysis. Can Urol Assoc J 2009;3:323-30.

22. Salinas CA, Kwon EM, FitzGerald LM, et al. Use of aspirin and other nonsteroidal antiinflammatory 
medications in relation to prostate cancer risk. Am J Epidemiol 2010;172:578-90.

23. Prater M, Shehata M, Watson CJ, et al. Enzymatic dissociation, flow cytometric analysis, and culture of normal mouse mammary tissue. Methods Mol Biol 2013;946:395-409.

24. Volovitz I, Shapira N, Ezer H, et al. A non-aggressive, highly efficient, enzymatic method for dissociation of human brain-tumors and brain-tissues to viable singlecells. BMC Neurosci 2016;17:30.

25. Rodríguez-González R, Baluja A, Veiras Del Río S, et al. Effects of sevoflurane postconditioning on cell death, inflammation and TLR expression in human endothelial cells exposed to LPS. J Transl Med 2013;11:87.

26. Song Y, Zhao H, Liu J, et al. Effects of Citral on Lipopolysaccharide-Induced Inflammation in Human Umbilical Vein Endothelial Cells. Inflammation 2016;39:663-71.

27. Zhang D, Zhou J, Ye LC, et al. Autophagy maintains the integrity of endothelial barrier in LPS-induced lung injury. J Cell Physiol 2018;233:688-98.

28. Rodrigues FS, Souza MA, Magni DV, et al. $\mathrm{N}$-acetylcysteine prevents spatial memory impairment induced by chronic early postnatal glutaric acid and lipopolysaccharide in rat pups. PLoS One 2013;8:e78332.

29. Kim YS, Kim JS, Kwon JS, et al. BAY 11-7082, a nuclear factor- $\kappa \mathrm{B}$ inhibitor, reduces inflammation and apoptosis in a rat cardiac ischemia-reperfusion injury model. Int Heart J 2010;51:348-53.

30. Zhang L, Altuwaijri S, Deng F, et al. NF-kappaB regulates androgen receptor expression and prostate cancer growth. Am J Pathol 2009;175:489-99.

31. Shukla S, MacLennan GT, Fu P, et al. Nuclear factor$\mathrm{kappaB} / \mathrm{p} 65$ (Rel A) is constitutively activated in human prostate adenocarcinoma and correlates with disease progression. Neoplasia 2004;6:390-400.

32. Sweeney C, Li L, Shanmugam R, et al. Nuclear factorkappaB is constitutively activated in prostate cancer in vitro and is overexpressed in prostatic intraepithelial neoplasia and adenocarcinoma of the prostate. Clin Cancer Res 2004;10:5501-7.

33. Lessard L, Mes-Masson AM, Saad F. NFkappaB : a new marker kappable of predicting prostate cancer outcome. Bull Cancer 2006;93:891-9.

34. Lepor H, Kaci L. The impact of open radical retropubic prostatectomy on continence and lower urinary tract symptoms: a prospective assessment using validated self-administered outcome instruments. J Urol 2004;171:1216-9.

35. Jaganathan A, Chaurasia P, Xiao GQ, et al. Coactivator MYST1 regulates nuclear factor- $\kappa \mathrm{B}$ and androgen receptor functions during proliferation of prostate cancer cells. Mol Endocrinol 2014;28:872-85.

36. Morgan MJ, Liu ZG. Crosstalk of reactive oxygen species and NF- $\kappa$ B signaling. Cell Res 2011;21:103-15.

37. Zabaleta J, Lin HY, Sierra RA, et al. Interactions of cytokine gene polymorphisms in prostate cancer risk. Carcinogenesis 2008;29:573-8.

38. Zabaleta J, Su LJ, Lin HY, et al. Cytokine genetic polymorphisms and prostate cancer aggressiveness. Carcinogenesis 2009;30:1358-62.

39. Kwon EM, Salinas CA, Kolb S, et al. Genetic polymorphisms in inflammation pathway genes and prostate cancer risk. Cancer Epidemiol Biomarkers Prev 2011;20:923-33.

40. Smith PC, Hobisch A, Lin DL, et al. Interleukin-6 and prostate cancer progression. Cytokine Growth Factor Rev 2001;12:33-40.

41. Schwabe RF, Wang TC. Targeting liver cancer: first steps toward a miRacle? Cancer Cell 2011;20:698-9.

42. Katz B, Reis ST, Viana NI, et al. Comprehensive study of gene and microRNA expression related to epithelialmesenchymal transition in prostate cancer. PLoS One 2014;9:e113700.

43. Kalluri R, Weinberg RA. The basics of epithelialmesenchymal transition. J Clin Invest 2009;119:1420-8.

44. Reis ST, Pontes-Júnior J, Antunes AA, et al. Tgf- $\beta 1$ expression as a biomarker of poor prognosis in prostate cancer. Clinics (Sao Paulo) 2011;66:1143-7.

45. Xu J, Lamouille S, Derynck R. TGF-beta-induced epithelial to mesenchymal transition. Cell Res 2009;19:156-72.

(English Language Editor: B. Meiser)

Cite this article as: Wang GC, Huang TR, Wang KY, Wu ZL, Xie JB, Zhang HL, Yin L, Tang WL, Peng B. Inflammation induced by lipopolysaccharide advanced androgen receptor expression and epithelial-mesenchymal transition progress in prostatitis and prostate cancer. Transl Androl Urol 2021;10(11):4275-4287. doi: 10.21037/tau-21-964 